\title{
Os estigmas da Paixão de Cristo: dois casos de invenção ou de impostura mística*1
}

The stigmata of the Passion of Christ: two cases of invention or mystical invention

Romuald Hamon*2

Apesar da rarefação de casos de estigmatização cristã, o interesse por esse fenômeno corporal insólito perdura. Um estudo dos casos Madeleine Lebouc e Yvonne-Aimée de Jesus revela que seus estigmas derivam ou de uma automutilação ou de uma farsa. No entanto, este não é o ponto essencial. Mais frutifera ainda mostra-se a pesquisa focada nesse modo original de relação do sujeito a seu corpo, e principalmente por que ele se sustenta em uma relação mística com Jesus. Orientando-se pela teoria freudiana e lacaniana, o presente artigo demonstra, a partir da clínica, as duas funções principais dos estigmas para esses dois sujeitos, a saber: o tratamento de um gozo louco pertencente ao corpo próprio e a emergência de um processo de representação permitindo assumi-lo e tratá-lo.

Palavras-chave: Misticismo cristão, estigma, simulação, feminilidade, psicose, gozo

*1 Tradução de Mila Signorelli.

*2 Université Rennes (Rennes, França). 


\section{ARTIGOS}

Muito embora a mística se encontre em declínio, as pessoas marcadas pelos estigmas de Cristo continuam a nos fascinar (Luzzatto, 2007; Menétrey-Monchau, 2010; Kechichian, Khoury, Richa \& Tomb, 2018). As feridas nos pés, mãos, testa e lados do corpo são famosas por serem sobrenaturais: elas transpiram de acordo com o ciclo litúrgico da Paixão de Cristo para cicatrizarem instantaneamente ou então persistirem, na ausência de supuração e de putrefação. Essas características pouco comuns não são suficientes para autentificar uma estigmatização: a relação ao divino que sustenta a manifestação deve corresponder ao ensinamento católico, a espiritualidade do estigmatizado deve ser imaculada e a postura dolorosa dos estigmas passa, após a morte, por uma análise meticulosa que avalia sua qualidade carismática. Eleitos para reiterar em sua carne os sofrimentos de Cristo, supõem-se que os estigmatizados dedicam-se à salvação das almas. A participação no arrependimento contribui para a consagração destes no seio da Igreja. No entanto, o fascínio dos estigmas é um prodígio divino tão louvado quanto controverso. Os teologistas elevaram o paradoxo à condição de critério podendo legitimar a graça, ao reconhecerem que os estigmatizados são "cópias de Jesus, vestidos de sinais de contradição, abandonados às disputas dos homens". E não é raro que "Deus perturbe a vista daqueles que os examinam. Assim, enquanto alguns os creem santos, amigos de Deus e encarregados de uma missão providencial, outros suspeitam de sua impostura ou atribuem seus carismas às taras fisiológicas ou psicológicas" (Garrigou-Lagrange \& Lavaud, 1936, p. 207; tradução livre). Assim, distinguir o verdadeiro do falso não é tarefa fácil, já que aquilo que parece ser uma impostura pode constituir a prova de uma estigmatização. De fato, o estudo de diversos casos mostram que os machucados divinos são falsificados. O que temos então diante de nós? Uma pura simulação ou algo que, ao 
aparentar-se a uma simulação, esconde um verdadeiro prodígio divino? Duas estigmatizadas, uma desaprovada pelos eclesiásticos, outra à espera de ser beatificada, permitem levar adiante nosso questionamento.

\section{A dolorida farsa de Yvonne-Aimée de Jesus}

Em 1960, o processo de beatificação da irmã agostiniana Yvonne Beauvais, de nome religioso Yvonne-Aimée de Jesus ${ }^{1}$ foi interrompido. Ela foi qualificada de "neurótica fabuladora procurando fascinar aqueles que dela se aproximavam" (Laurentin \& Mahéo, 1993, p. 186; tradução livre). Dentro dessas circunstâncias, a Igreja silenciou seu caso. Tal posição foi invertida com a pressão dos fiéis. Desde então, o Padre Laurentin inventa sua hagiografia e coleciona os testemunhos que confirmam a manifestação de seus estigmas entre 1924 e 1943 . Ao serem estudados, os estigmas se revelam terem sido realizados em segredo e as feridas simuladas. Alguns exemplos: "Ao voltar das laudes, testemunha Madre Ange Gardien, ela me mostra seu lenço cheio de sangue. Eu a deixo para que se cuide e volto mais tarde. Ela estava em sua cama, sentada, o sangue escorria"; "Não posso dizer, testemunha o Padre Tonquédec, que estive o tempo inteiro a observá-la [...] Uma vez que o sangue já não escorria, limpamos e nenhuma ferida, nenhum arranhão aparece" (Laurentin, 1988, pp. 60-71; tradução livre).

Essa máscara ensanguentada é comparável aos panos escarlates com os quais ela se enrola no convento de Malestroit para sugerir a presença dos estigmas. Sua relação epistolar carrega também os traços dessa farsa. Em 1941 ela envia ao Padre Labutte um pedaço de tela maculada acompanhada das seguintes palavras: "Sangue proveniente do coração após uma flechada". Ela reitera esse erro: Esta noite minhas mãos inflamam e um inchaço vermelho produz-se dentro e em cima de minhas duas mãos (...) eu ainda consigo escrever mas sem apoiar muito (...) Peço desculpas pela mancha: uma pequena gota de sangue, caída da palma direita. Eu não a apago. Ela tem a forma de um prego" (Laurentin, 1988, p. 99; tradução livre). Concluir parece fácil: ela realiza uma impostura. Entretanto, ela atesta que seus estigmas têm origem divina.

* "Aimée de Jesus" é um sobrenome que podemos traduzir como "Amada de Jesus" (N. da T.) 


\section{ARTIGOS}

O divino ela de fato experimenta. Analisado, seu testemunho é duplo: loquaz ou sem palavras. O primeiro é o Dieu-dire (Lacan, 1972-1973/1975, p. 44) do imaginário feliz com suas ilusões histéricas. Com o aval de Jesus, ela realiza suas mais caras vontades e se dedica às palavras de amor que a fazem suspirar: "A voz de Jesus tão bela e tão suave, tão plena de amor me disse: os Anjos te chamam a Amada do Rei do amor" (Labutte, 2000, p. 193; tradução livre). Essas mensagens celestes abundam. Porém, o Jesus desse belo devaneio se distingue, mesmo se ela o confunde, daquele que ela experimenta de modo inefável no êxtase. Ela é incapaz de traduzir a experiência ou dela restituir qualquer tipo de conhecimento: "Todo esse inexpressível me oprime. Oh união suprema! Oh delícias do amor divino, do Amor infinito! Do infinito inexpressível! Eu, ser finito, eu vislumbrei o infinito. Mas eu acumulo as palavras e as palavras são vazias, as palavras são vãs, as palavras não são nada diante do Infinito" (Yvonne-Aimée de Malestroit, 1987, p. 121; tradução livre). Ela não consegue transpor para a língua seu encantamento, mas acredita estar na presença de Jesus; o que pode surpreender mesmo que seja da natureza de Deus conservar invioladas suas trevas (Almeida Silva, Facchinetti \& Brilhante Kury, 2011). A menos que se acredite que o próprio incomunicável faz com que ela suponha alimentar uma relação mística com ele. A elaboração lacaniana sobre a feminilidade é preciosa para uma melhor compreensão deste caso.

Enfim, lembremos que a anatomia não faz a sexuação do sujeito. Esta última regula-se, para ambos os sexos, a partir da relação do sujeito ao Um fálico; ou seja, ao significante ímpar que é $\Phi$, o falo simbólico. ${ }^{1}$ Mais exatamente, Lacan estabelece, no decorrer dos anos 1970, o diferencial das identidades sexuais inconscientes em função da inscrição dos sujeitos na função fálica. As fórmulas da sexuação do Seminário XX o demonstram (Miller, 1997,

${ }^{1} \Phi$ é "um significante sem par” (Lacan, 1958/1966b, p. 642). Ele é o único significante que diz o sexo no inconsciente. Fiel à Freud, Lacan o posiciona como um universal válido para todos os sujeitos, em razão da ausência, no inconsciente, de um significante capaz de identificar o feminino. Daí o impossível da relação sexual, já que a lógica da relação entre os sexos não pode ser escrita; consequência da forclusão do significante "A mulher" (Lacan, 1973/2001c, p. 537). E precisamente, $\Phi$, por não ter par, é ao mesmo tempo a causa e a máscara da não relação sexual. Ele a causa porque o inconsciente é unissex, fálico. E, ao enunciar o que se deve fazer enquanto homem ou mulher, ele mascara a inexistência, compensando assim a ausência de um Outro sexo que o fálico (Lacan, 1972/2001a, p. 458). 
1998, 1999; Hamon, 2010a; Moreira Marcos, 2011). Nos andares inferiores do quadro da sexuação relativo à neurose, as fórmulas distribuem as duas modalidades pelas quais os sujeitos neuróticos são servos da função fálica $(\Phi)$ e do gozo a ela ligado; aquele gozo que, com a linguagem, sofreu o golpe da castração: o gozo fálico.

Assim, os homens - os sujeitos em posição masculina do ser — são todos e totalmente submissos à função fálica que é a mesma da castração. Esta última consagra a virilidade e os homens relacionam-se apenas com o gozo fálico; quem tem a linguagem é o aparelho (Lacan, 1972-1973/1975, p. 52). Esse gozo é tão limitado e descontínuo como o próprio significante. Com a mediação da fantasia, ele encontra satisfação em objetos fora do corpo e falicizados; satisfação que se desenvolve sobre o fundo da falta do objeto $a$.

As mulheres — os sujeitos em posição feminina do ser — não constituem um conjunto, já que não existe uma identidade especificamente feminina, mas também porque elas são, de variadas maneiras, nãotodas submissas à função fálica (Vinciguerra, 2014). A castração não funciona como regra para todo o campo do gozo feminino. Cada mulher é dividida entre $\Phi$ e $\mathrm{S}(\mathbb{A})$ entre a ordem fálica da linguagem e um fora da linguagem que $\mathrm{S}(\mathbb{A})$ o significante a menos no universo do discurso - escreve. O gozo da mulher se desdobra entre o gozo fálico e um suplemento que se compõe além do falo, fora da representação (Lacan, 1972-1973/1975, p. 75). Encontrar-se nesse gozo suplementar que dispensa o significante é impossível já que ele é destituído de linguagem. Ele faz da mulher uma perdida porque provoca a falha do regime fálico do inconsciente, destruindo os assentos identificatórios (Soler, 2006). Enquanto experiência, ele faz com que uma mulher se ausente de si própria. As deserções subjetivas que ele provoca permanecem marcadas pelo selo da ignorância. Diferente do gozo na psicose, ${ }^{2}$ esse gozo é "radicalmente

${ }^{2} \mathrm{O}$ gozo Outro do sujeito neurótico feminino e o gozo do Outro, com o qual lida um sujeito psicótico são insubmissos à lei do significante e da castração, porém de maneiras distintas (André, 1998). O gozo Outro produz-se pela subtração da função fálica $(\Phi)$, mas permanece limitado por ela. Sem objeto, ela possibilita relação com o Outro barrado. O significante e o sentido não têm poder sobre este gozo. Sua alteridade permanece radical. O gozo do Outro, ligado à não subtração do objeto $a$, produz-se pela invasão e não é limitado pela função fálica em razão de sua carência na psicose. Esse gozo coloca o sujeito em relação com um Outro compacto. Uma elaboração significante e uma invenção de sentido podem assegurar o tratamento. 


\section{ARTIGOS}

Outro" (Lacan, 1972-1973/1975, p. 77; tradução livre). Ele investe o corpo próprio de forma abertamente dolorosa.

Nos anos 1920, Beauvais é vítima de um sofrimento que não é o do sintoma: "O corpo todo me dói. Todo o meu ser me faz sofrer". "Os mal-estares bizarros" que se associam fazem-lhe supor que ela não está "doente de uma doença comum" (Laurentin \& Mahéo, 1993, p. 36; tradução livre) e conduzem-na a Deus em 1922: "Eu não posso expressar nada do que acontece; não é da terra" (Laurentin, 1999, p. 338; tradução livre). "Há momentos em que sofro muito. Esse sofrimento indefinível não me afasta de Jesus. Pelo contrário!". No final de 1923, ela atribui a Jesus esse gozo que a ausenta dolorosamente dela mesma e que permanece tanto inefável quanto desprovido de sentido: "Ah se eu pudesse falar, mas eu não posso! Meu sofrimento foi compreendido apenas por Jesus" (Yvonne-Aimée de Malestroit, 1987, p. 217; tradução livre). Ao conectar seu sofrimento aos impenetráveis divinos, ela assegura-se de um parceiro a quem dedicar o indizível na medida em que ele coloniza o abismo sem nome dentro do qual ela se perde. O significante "Jesus" identifica e designa de onde ela se eclipsa como sujeito do significante: em Deus e seus mistérios.

A saída mística como solução para compor com o gozo do Outro não lhe é suficiente. Além de — ponto que retomaremos adiante - adotar o nome de Yvonne-Aimée de Jesus, ela simula os estigmas a partir de 1924; simulação que a ultrapassa. Ela não tem como finalidade abusar do outro, mesmo se ela é obrigada a passar por isso para autentificar sua mística. Ela utiliza um artifício no qual ela própria acredita. O imaginário feliz de suas ilusões histéricas não apenas a fascinam: ela é principalmente cativada pela aura de Cristo que a envolve quando diante dos fiéis. Ao exaltarem-se diante de suas marcas divinas, os fiéis alimentam a atmosfera sobrenatural. Assim, Beauvais é subjugada pelo mistério que ela suscita já que esse último reflete a estranheza que lhe é familiar dentro da parte de si mesma que se lhe escapa e que, para ela, nada mais é senão celestial. Sobre isso, ela nada pode dizer, mas pode indexá-lo. Ao fazer aparecer e depois desaparecer as feridas, ela dá corpo, por meio dessa cadência eclíptica, à sua relação contingente e fora da linguagem ao gozo Outro, a Jesus (Hamon, 2010b). Mas não só. Ao usar, segundo as vias consagradas, a postura dolorida dos estigmas, ela molda o sofrimento inefável que ela estima relacionado a tal postura. Ela sofre essa dor, para ela de origem divina, que é testemunho do amor eletivo com o qual Jesus a associa à sua dolorosa Paixão. Ela compreende a componente salvadora "Minha cruz (seus estigmas) anuncia uma recrudescência do sofrimento, minha alma agora, com 
a graça de Deus e do amor, encontra descanso na dor. Antes, esse isolamento e essa dor me traziam amargura ao tirarem minha paz" (Laurentin, 1999, p. 176; tradução livre). Assim, Jesus eleva-a de sua parceria com a solidão, de um gozo não identificante, para inseri-la na rede simbólica do discurso da Paixão de Cristo. Porém, quando esse nó se desfaz, o gozo deixa de ser limitado pelas representações religiosas. Tal "desequilíbrio espiritual” acontece em 1943 com o falecimento do Padre Crété, seu diretor de consciência que a amava em razão de sua relação com Jesus (Yvonne-Aimée de Malestroit, 1987, p. 230). Ao deixar de sustentar o milagre, a simulação dos estigmas dissipa-se à medida que a noção do divino se ausenta. Yvonne afunda-se então numa aflitiva dor sem nome, em que a única parceira é uma tristeza indefinível em seus eclipses dela mesma (Labutte, 2000, pp. 578-632).

Ao dedicar seu sofrimento inefável à salvação das almas, Beauvais dota-se de um manual de instruções religioso para lidar com o gozo Outro, com o qual ela naturaliza a opacidade estrangeira, rendendo-a identificável para os eclesiásticos. Beauvais o conduz assim à civilização, ao coletivizá-lo. Dessa opacidade ela faz um objeto que pode ser partilhado por todos os fiéis. Dessa forma ela reforça os laços comunitários ao avivar a crença. Mas trata-se de uma solução frágil. A suspeita de impostura que ela enfrenta em 1927 ilustra essa hipótese.

Sem conseguir curar sua Madre Superiora de um câncer pela substituição reparadora, sua estigmatização é presumida como fraudulenta. Ela simula então uma relação epistolar com Odette de Montlo. As cartas desta última são endereçadas às religiosas do convento. Odette escreve que foi salva de um mal incurável por Beauvais e ela lamenta as injustas humilhações que sofre a estigmatizada (Laurentin, 2000, pp. 55-190). Graças a essas cartas, Beauvais será novamente magnificada até que o capelão do convento descobre que Odette não existe. ${ }^{3}$ Odette ninguém mais é do que Beauvais. Mesmo que inquieta, ela não confessa sua infração. Seu bispo a salva em 1929, ao suscitar dúvidas sobre o capelão no momento da morte da Madre Superiora. Essa correspondência fictícia é sustentada pela lógica da mascarada feminina. Por trás da máscara de Odette, Beauvais reclama dos maus tratamentos que ela sofre e tenta provar a origem divina de seus êxtases e de seus estigmas, assim como o caráter divino destes.

${ }^{3} \mathrm{O}$ Padre Bruneau prova que a caligrafia e o estilo de Odette são de Beauvais e que ambas cometem os mesmos erros ortográficos (Laurentin, 2000, pp. 180-189). 


\section{ARTIGOS}

A partir da não possessão do significante, já que ela o dispensa, Beauvais tenta dar um predicado de existência ao gozo Outro ao referi-lo a Jesus. Com a manifestação dos estigmas, ela faz figurar o gozo a partir de uma estetização sangrenta, expressão de seu doloroso mistério. Ao divinizar o abismo sem nome dentro do qual ela se abole e ao apropriar-se de um fenômeno sobrenatural para traduzir seu sofrimento inefável, ela revela a parte de si própria que é subtraída da linguagem. Ao dedicar seu sofrimento a Jesus, ela faz com que ele seja reconhecido por um processo de representação que assume tal função. Antes de adotar ares de crucificada em 1924, ela inventa de fato para si um nome divino "Yvonne-Aimée de Jesus", que a consagra como esposa de Jesus e com o qual ela entra na sua ordem religiosa em 1927. Tal criação significante revela o gozo Outro ao mesmo tempo que o civiliza, ao subjetivar-lhe pelo significante "Jesus" ao qual ele se articula. Muito antes de tornar-se agostiniana hospitaleira e de assim amarrar o Outro que ela é para si própria a "Jesus", Yvonne Beauvais já havia tentado nomear-se Outra. Na época, ela já publicava romances, que apareciam como folhetins no jornal L'Echo de Paris, sob um pseudônimo que pressagiava seu futuro misticismo. Seu nome de escritora era "Dyvonne" (Labutte, 2000, p. 297).

Seus estigmas permitem-lhe desvelar sua posição subjetiva não toda representada pelo simbólico. Dessa forma, ela conseguiu, como veremos, realizar um verdadeiro milagre sobre a cena religiosa, enquanto Madeleine Lebouc esperava por sua vez a legitimação no campo médico.

\section{A transformação santificante de Madeleine Lebouc}

A obra de Pierre Janet De l'angoisse à l'extase (Janet, 1926/1975a; Janet, 1926/1975b) na qual Madeleine Lebouc, aliás Pauline Lair Lamotte, é tida como caso paradigmático para explicar cientificamente a experiência mística e os estigmas cristãos conheceu um verdadeiro sucesso. Como resposta, o Padre Bruno de Jesus Marie colocou em causa a espiritualidade de Madeleine ao chamar atenção para sua tendência para a abjeção e considerando seus fenômenos extáticos como patologias (Jésus Marie, 1931). No mais, os eclesiásticos consideram que Janet nunca obteve "um estigma verdadeiro e certo" por serem raros, pela ausência de consagração do sofrimento de Madeleine a serviço da salvação e, principalmente, por causa do resultado de uma experiência da qual ela foi objeto (Maître, 1993, p. 19; tradução livre). Para provar que as feridas derivam de uma autossugestão de tipo histérico, Janet equipou-a 
com um sofisticado aparelho de controle. O resultado foi nulo e, além disso, Janet indica que ao surpreendê-la em flagrante delito, Madeleine se mutila e aperfeiçoa suas feridas para que elas tomem o aspecto de estigmas (Janet, 1926/1975a, p. 397). O motivo pelo qual ela se inflige estigmas por volta de vinte vezes na Salpêtrière* pede um questionamento, assim como sua sintomatologia. Esta última deixa Janet perplexo: "É raro ver um mesmo indivíduo apresentar sucessivamente quase todas as formas de doença mental (...) Podemos diagnosticar a histeria, a psicastenia, a melancolia ou a agitação maníaca" (Janet, 1926/1975b, p. 468; tradução livre). Com análise dos estados que ela experimenta, um diagnóstico de psicose maníaco-depressiva pode ser defendido. Ele permite questionar sua estigmatização e sua constante maneira de andar sobre a extremidade da ponta dos pés, que é para ela a marca de "sua eleição divina e de sua assunção celeste" (p. 400).

Sem desenvolver para além do necessário (Hamon, 2008), precisemos o motivo da "carreira de pobre menina" (Janet, 1926/1975a, p. 121) que ela vive, sob seu pseudônimo, durante os anos 1874-1893 nos bas-fond parisienses, sobrevivendo de pequenos trabalhos de operária. Ela abraça esta "vocação" para restringir "o gozo insalubre e perigoso (do) prazer imoderado" que a invade durante as relações sociais e que a aspira, segundo sua interpretação, em direção à "loucura mundana" (Janet, 1926/1975a, pp. 338-341; tradução livre). Madeleine, "sujeito do gozo" (Lacan, 1966/2001b, p. 215; tradução livre), tenta restringir este último pela focalização em uma vida regrada pelo ideal da pobreza do discurso franciscano que seu diretor de consciência, o Padre Conrad, defende. Com o seu falecimento em 1893, o para -psicose de Madeleine explode. Mergulhada em uma atmosfera de fim do mundo, ela envia uma carta ao governador na qual revela a existência de um comércio de cadáveres de operários pobres (Janet, 1926/1975a, p. 145). Esse texto suscita sua internação no hospital Necker em Paris no mês de março de 1894. Ela apresenta um quadro de surto maníaco, origem de sua impressionante maneira de andar sobre a ponta dos pés. Esse transtorno do movimento a propulsiona à Salpêtrière em fevereiro 1896. Ali ela experimenta sucessivamente o equilíbrio, as tentações, a seca, a tortura, as consolações. Em seu

* Famoso hospital parisiense construído no século XVII, que durante séculos serviu como asilo para prostitutas e doentes psiquiátricos. Jean-Martin Charcot foi um dos seus mais conhecidos professores, tendo recebido Freud em seu serviço. Hoje é um centro hospitalar universitário que engloba diversas especialidades médicas. (N. da T.) 


\section{ARTIGOS}

delírio, esses estados nomeiam e fixam repartições do gozo do Outro. Ela designou uma localização significante para cada uma das diferentes sensações do gozo louco do qual é objeto durante as reversões de sua psicose maníaco-depressiva; e isso ao articular-lhes às representações religiosas dos graus místicos.

O equilíbrio nomeia a ponderação de sua labilidade emocional. Sua estabilidade marcará o fim de sua internação em 1904. Durante as tentações, ela afronta uma fuga de ideias e aparece entregue à metonímia pura da cadeia significante: "É em vão que tento parar, nada pode impedir a vagabundagem de meu pobre espírito (...) Não posso realizar nenhuma ação por causa dos pensamentos que me agitam indefinidamente em todos os sentidos" (Janet, 1926/1975a, p. 132; tradução livre).

A seca antecipa o estado de tortura durante o qual ela se cadaveriza, ao mesmo tempo que sente ser o objeto do gozo desenfreado do Outro demoníaco que, como ela o alucina, a penetra: "O demônio conseguiu novamente fazer coisas assustadoras (...) eu estava amarrada a um cadáver e o frio do cadáver é que penetrou! É o Diabo que quer penetrar em mim e essa penetração me causa dores horríveis" (p. 148). Enquanto seu sentimento de culpa transforma-se em convicção, ela se autodifama. Ela se sente "condenada" e, nota Janet, "responsável não apenas por seus erros, mas também pelos erros dos outros". O risco de uma passagem ao ato é onipresente. "Ela fala em atirar-se do alto das escadas" (p. 147). Na tendência melancólica de sua psicose, ela identifica-se com o objeto a (Lacan, 19621963/2004, p. 388; Tyszler, 2011; Tenório \& Costa-Moura, 2014)). Sua encarnação de objeto dejeto do simbólico empurra-a para evacuar-se da cena do mundo; principalmente quando ela está envolta nos suplícios do inferno nos quais seus "órgãos queimam alternadamente todos juntos" (Janet, 1926/1975a, p. 147; tradução livre). Durante essa hipocondria, o significante desencadeia-se no real, sonorizando-lhe sua infâmia. Inclusive, é na correspondência entre vozes alucinadas que a designam enigmaticamente, "Lebouc", que ela assim se nomeia: "Eu obedeci sem entender as vozes que eu ouvia (...) A certeza que eu era o bode expiatório* me fez adotar totalmente meu novo nome" (pp. 82-83).

* Em francês, bouc emissaire. Daí a construção de seu novo nome, Lebouc, composto a partir do pronome indicativo masculino "le" ("O") e do substantivo "bouc" ("bode"). Lebouc seria o equivalente, em português, de Obode. (N. da T.) 
Nas consolações que se sucedem às torturas, Madeleine faz de Deus a entidade de gozo que a exalta. Esse Outro compacto e barulhento, intrusivo e enigmático. Ele não tem para ela, escreve Janet, "nada de desconhecido e de impenetrável" (Janet, 1926/1975a, p. 375). Não se trata do parceiro evanescente e sem palavras de um sujeito neurótico em posição feminina de ser. Sob o poder de Deus, ardores loucos, extáticos, apoderam-se de Madeleine: "Eu as vezes sinto uma necessidade suprema de dançar, vou acabar por saltar no ar. Tenho em mim uma espécie de eletricidade, de vapor comprimido que parece estar pronto para explodir" (pp. 91-92). É nessa embriaguez mortífera dessa ausência de ponderação que seu caminhar sobre a ponta dos pés atinge seu ápice. Em seu delírio, esse fenômeno marca para ela sua assunção espiritual.

Quando o estado de tortura reverte-se em estado de consolação, o gozo do Outro vira beato. Seu corpo é percorrido de "arrepios puros e divinos que a intoxicam da volúpia dos felizes" (p. 95). Os beijos de Deus que ela sente sobre sua uretra fazem-lhe carícias contínuas (p. 94). Uma significação, a da santificação, dá sentido e canaliza o gozo louco dentro da tendência maníaca da sua psicose. Ela sente-se "divinizada" e "as partes de seu corpo parecem-lhe santas" (p. 106): "a carne que aparece morta para as sensações doentes - ela refere-se aqui ao prazer ilimitado que controlava durante sua existência miserável - aparece bem viva para os prazeres puros divinos" (p. 95); "assim como todos os meus sentidos e todos os membros do meu corpo, as partes sexuais têm seus prazeres transformados, ao virarem todas particulares, espirituais e tão puras" (p. 107). Seus estigmas e seu caminhar assumem a função de demonstrar essa transformação santificante.

Durante as consolações, ela sente-se de fato "purificada de todos os pecados possíveis", "bastante avançada na santificação" (p. 106), mas teme ser "incompreendida e permitir confusão entre as volúpias perigosas, doentes e aquilo que é puro e casto" (p. 128). A falta de convicção nessa ficção megalomaníaca leva-a a buscar a prova no imaginário; para tal, apoia-se sobre sua singular maneira de andar que, para ela, marca literalmente sua elevação santa. Ela espera uma prova divina indiscutível (Maître, 1993, p. 257). É por essa razão que consente em realizar a prova da balança através da qual Janet tenta convencê-la que não é levantada por Deus, já que seu peso não é alterado. Madeleine, por sua vez, espera de Janet que ele a ajude a realizar "obras-primas", uma assunção miraculosa (Janet, 1926/1975a, p. 114). Tal submissão ensina algo sobre a facticidade de sua "transformação em corpo glorioso" (p. 77), tal como ela chama a mutação de sua imagem do corpo pela prestigiosa significação fálica que aureola tanto suas feridas quanto seu 


\section{ARTIGOS}

caminhar. Numa constante "exposição", ela toma Janet como testemunha "de sua posição do crucificado e de sua posição de assunção ao céu" (p. 113) que são para ela "as prerrogativas divinas dos corpos glorificados" (p. 86); isso para que Janet legitime sua santificação. Os textos que ela lhe endereça também servem para convencê-lo. Ela só pode apreender a santa representação idealizada de si mesma através do espelho do outro; através de Janet, que na transferência encarna "São José" (p. 375) ou "um órgão da divindade" (p. 415), enquanto durante as torturas ele é um emissário do diabo que a submete a experiências de vivissecção (p. 145).

Sem conseguir inscrever-se sob o traço unário para edificar seu Ideal do eu, Madeleine permanece colada ao registro do imaginário ao buscar a referência de sua singularização $\left(\mathrm{S}_{1}\right)$. Sua dependência da opinião de Janet é prova disso, tanto quanto sua apropriação dos estigmas. Em sua época, o significante estigmas está em voga na psiquiatria para nomear fenômenos próprios da histeria. Segundo o que se diz dela na Salpêtrière, o significante lhe faz sentido a partir do discurso religioso. As cartas à sua irmã ilustram esse ponto: "Ouvi falar de 'estigmas' (...) nos vemos como o objeto de uma estima. Porque é certamente uma graça do bom Deus" (Maître, 1993, p. 243; tradução livre). Em setembro de 1896, ela escreve: "O médico me disse que ele esperava os estigmas" (p. 247). Em novembro ela os apresenta. Ela produz em si mesma as marcas para se conformar à imagem ideal, percebida por ela, no desejo de Janet a seu respeito. Ele foi, involuntariamente, instigador de seus estigmas.

Por sua transformação em corpo glorioso, Madeleine tenta construir um corpo falicizado por uma imagem de santidade que lhe garante que o gozo fora-da-lei que a parasita é mais puro e são do que doente. Em sua tentativa de ser como os santos, ela tenta compensar a falta do significante unário $\left(\mathrm{S}_{1}\right)$ com um traço, não desprovido de megalomania, que ela colhe na religião. Tenta se representar como única, ao conformar-se à imagem dos santos, baseando-se no caráter eletivo desse estatuto. A ausência de fundamento de tal compensação da marca diferencial do sujeito $\left(\mathrm{S}_{1}\right)$ nunca é tão visível quanto quando o semblante de santidade se esgota: "Será que não passo uma ideia falsa da santidade? Tenho medo de ser uma falsificação dos santos" (Janet, 1926/1975a, p. 129; tradução livre). Essa pseudo-identidade heróica se eclipsa quando Janet deixa de sustentá-la ou quando as elações maníacas revertem-se em abismos melancólicos. Madeleine tem então a sensação de ser uma rejeitada e possui a conviç̧ão de que a religião é insultada por sua causa (p. 253). Durante o estado de tortura, essa falsificação dos santos espanta-lhe: 
"Eu sou o brinquedo do demônio. É ele que me faz andar na ponta dos pés, que deixou marcas nos meus pés" (p. 146).

\section{Um-postura ${ }^{4}$ e invenção mística}

A paixão de Madeleine Lebouc não é como a de Yvonne Beauvais. Entretanto, mesmo se elas se asseguram de tal solução de maneiras distintas, segundo suas posições quanto à castração, os estigmas assumem para ambas uma dupla função: o tratamento de um gozo louco pertencente ao corpo próprio - Outro ou do Outro - combinado à aparição e à manutenção de um processo de representação que lhes permite assumir a relação. Interessaremo-nos por esta última porque ela está por trás do uso que cada uma delas faz dos estigmas, assim como faz, em matéria de mística, a "Um-postura" de uma e a invenção de outra.

Ao se apropriar dos estigmas para se fazer um corpo glorioso e santificado, Madeleine "mostra a todos sua unidade" (Lacan, 1946/1966a, p. 172; tradução livre) na Salpêtrière. Sua mística é uma "Um-postura". Ela não é inautêntica como dizem os religiosos e nem deriva de uma "simulação", como afirma Janet (Janet, 1926/1975a, p. 400). Trata-se de uma postura do Um, do Um unificante e não contábil. Esse Um do único que não abre para uma série $\mathrm{S}_{2}$, Madeleine o encarna de maneira conformista, imitando os Santos, reproduzindo os atributos dessas identidades gloriosas em que a exceção é consagrada e venerada no catolicismo. Ela se faz ícone a partir desse sistema. A prevalência do imaginário nessa tentativa de assegurar-se uma consistência unificada dela mesma através de um pseudo-eu ideal, aureolado de uma imagem fálica, não marcada pela castração, é manifesta. Madeleine busca constantemente a legitimação no espelho do outro; em Janet que a apoiou e favoreceu sua transformação em corpo glorioso com a qual ela tentou tratar o gozo deletério que se exerce sobre seu ser passivado e ao se conferir uma representação santa de si mesma.

Madeleine Lebouc foi considerada louca pelos eclesiásticos. Já Yvonne Beauvais encantou muitos deles pelo prodígio de sua participação mística com

${ }^{4}$ Un-posture é um neologismo, composto pelo pronome "Um" e pelo substantivo "postura". Un-posture engloba portanto a noção do Um ao mesmo tempo que remete a uma relação ambígua entre "postura" e "impostura'. Em francês, Un-posture e imposture possuem a mesma pronúncia. 


\section{ARTIGOS}

os sofrimentos de Cristo. Ela foi certamente levada a exagerar a encenação de sua farça dolorosa quando alguns acusaram-na de impostura. Donde a suspeita, no momento de sua beatificação, de uma mistificação do outro operando na sua ostentação dos estigmas. Mas assim estaríamos ignorando a carga da saída mística que ela inventou para lidar com seu gozo suplementar. Este último, lembramos, é sustentado pelo significante "Yvonne-Amada de Jesus" que ela cria para nomear-se Outro para si mesma antes de fingir as feridas carismáticas. Com esse nome divino, que a cadência sobrenatural dos estigmas corporiza em eclipses, ela civiliza e revela a parte de si mesma subtraída da linguagem. Ao identificar a origem a partir de onde ela se afunda e se deteriora, a fórmula "de Jesus" faz borda entre o lugar onde ela pode se dizer e o lugar onde é privada de significante, entre $\Phi$ e $S(A)$, amarrando-os. Essa criação significante é um apoio subjetivo, localizado no ponto a partir do qual uma mulher se "Autrepose", * entre gozo fálico e gozo Outro (Lacan, 1971-1972, lição de 8/3/1972); lugar de onde o seu gozo se desdobra entre $\Phi$ e $S(A)$. Nem $S_{1}$, nem suplência à ausência de um significante que poderia identificar o feminino no inconsciente, "de Jesus" é uma circunscrição significante de $\mathrm{S}(\mathrm{A})$. Ele bordeja o real e assim esculpe o impossível de dizer. Trata-se de uma criação que, tal como a do artista, não preenche o buraco deixado aberto por $\mathrm{S}(\mathrm{A})$ mas o revela ao fazer com que ele opere. Isso é o que Beauvais consegue, com excelência, realizar no contexto religioso: ao tomar ares de crucificada para desvendar sua parte Outra a si mesma, que escapa-lhe e que ela nomeou como sendo "de Jesus". Pela pia fraude que a ultrapassa, "Dyvonne" realiza um milagre: engendra Jesus nos homens ao fazer-lhe palpitar em sua própria carne, através do jogo de ausência e presença dos estigmas. Sugere a presença evanescente de uma Outra cena situada para além do simbólico e que escapa a todo fio ou rede de qualquer conhecimento. Ela sustenta, com seu gozo inefável e desprovido de sentido, uma face de Deus, aquela que não existe e que nada significa ao permanecer fora da linguagem (Lacan, 1972-1973/1975, p. 71). Com essa criação ex-nihilo, sua beatificação não deveria sofrer nenhum embaraço, pois ela inventa a mística enquanto tal.

* Com o neologismo "s'autreposer", Lacan coloca figura do Outro ("Autre") no lugar da locução "se poser entre", "se entrepor". O Outro se põe entre, ao mesmo tempo que se entrepõe (N. da T.). 


\section{Para concluir}

Yvonne Beauvais e Madeleine Lebouc recorreram ao discurso religioso sobre a mística para assumir, no cotidiano, o gozo Outro ou do Outro, com os quais elas estavam respectivamente em relação. Essa solução foi adotada por cada uma distintamente: Yvonne tornou-se a própria figura da solução; já Madeleine, ganhou corpo com os estigmas, experiência compartilhada por outros sujeitos. Alguns deles passaram a ser, posteriormente, modelos de santidade. A clínica dos místicos cristãos pertence à época dos dinossauros. Coloquemos mesmo assim a hipótese de que os sujeitos neuróticos em posição feminina de ser são ainda capazes de designar o lugar de onde eles se eclipsam, um distante fora da linguagem e desprovido de sentido, a partir dos impenetráveis divinos (Hamon, 2015) ou de deuses new age que eclodem em nossa modernidade. Os sujeitos psicóticos podem igualmente utilizar os mesmos para nomear e figurar o Outro do gozo com os quais eles tratam.

Alguns afirmam estar hoje em contato com entidades cósmicas e viverem sequestros extraterrestres (Maleval, 1997). Sem dúvida trata-se de distinguir os sujeitos que se sentem misteriosamente sequestrados por esses seres vindos do além dos sujeitos que se dizem enigmaticamente invadidos por eles. Tal distinção parece ainda mais necessária do que uma estigmatização moderna, através de implantes presumidamente alienígenas, que tendem a surgir para provar, através de diversas marcas corporais, essa relação extraterrestre. Será que devemos, então, concluir que alguns são exemplo de inventividade, ao sugerirem aos homens a existência de uma dimensão Outra, desafiando toda descrição de linguagem e conhecimento humanos, na qual eles se alojam? E que outros fazem ato de Um-postura ao adotarem como posição demonstrar a todos que eles fazem parte dos escolhidos desse mundo supraterrestre? Deixemos a questão aberta, lembrando que se o discurso da ficção científica, que sustenta a síndrome do sequestro extraterrestre, não forma ainda uma religião, grande número de nossos contemporâneos são capazes de acreditar e defender tais soluções subjetivas para assumir a relação ao gozo que não se regula pela função da castração, seja ele Outro ou do Outro. 


\section{ARTIGOS}

\section{Referências}

Almeida Silva S. de, Facchinetti, C., \& Brilhante Kury, L. (2011). Os êxtases da Irmã Germana: diferentes interpretações em torno das doenças nervosas no Brasil, Revista Latinoamericana de psychopatologia fundamental, 14(2), 329-345.

André, S. (1998). O que quer uma mulher? Rio de Janeiro, RJ: Zahar.

Garrigou-Lagrange, R., \& Lavaud, B. (1936). Les circonstances de la stigmatisation. Etudes carmélitaines, octobre 1936, 188-207.

Hamon, R. (2008). Madeleine Lebouc: Se faire un corps sanctifié par la religion catholique. L'évolution psychiatrique, 73, 41-52.

Hamon, R. (2010a). Jouissance et position féminine. In L. Jodeau-Belle, \& L. Ottavi, (dir.), Les fondamentaux de la psychanalyse lacanienne (pp. 231-243). Rennes, France: P.U.R.

Hamon, R. (2010b). La mascarade féminine des stigmates ou la splendeur des vérités et des réalités divines. Cliniques méditerranéennes, 81, 47-63.

Hamon, R. (2015). Une mystique moderne: Cécile Vé, l'Autre femme de Flournoy. Cliniques méditerranéennes, 91, 183-194.

Janet, P. (1975a). De l'angoisse à l'extase. Etudes sur les croyances et les sentiments, Tome

I. Réédité par la Société Pierre Janet et le Laboratoire de Psychologie pathologique de la Sorbonne. Paris, France: Alcan. (Trabalho original publicado em 1926).

Janet, P. (1975b). De l'angoisse à l'extase. Etudes sur les croyances et les sentiments, Tome II. Réédité par la Société Pierre Janet et le Laboratoire de Psychologie pathologique de la Sorbonne. Paris, France: Alcan. (Trabalho original publicado em 1926).

Jésus Marie, B. (de). (1931). À propos de la "Madeleine" de Janet. Etudes carmélitaines, avril 1931, 188-190.

Kechichian, E., Khoury, E., Richa, S., \& Tomb, R. (2018). Religious stigmata: A dermato-psychiatric approach and differential diagnosis, International journal of dermatology, 57(8), 885-893.

Labutte, P. (2000). Yvonne-Aimée de Jésus. Paris, France: F.X. de Guibert

Lacan, J. (1966a). Propos sur la causalité psychique. In J. Lacan, Ecrits (pp. 151-193).

Paris, France: Seuil. (Trabalho original publicado em 1946).

Lacan, J. (1966b). La direction de la cure et les principes de son pouvoir. In J. Lacan, Ecrits (pp. 585-645). Paris, France: Seuil. (Trabalho original publicado em 1958).

Lacan, J. (1971-1972). Le séminaire. Livre XIX. ... Ou pire. Inédit.

Lacan, J. (1975). Le séminaire. Livre XX. Encore. Paris, France: Seuil. (Trabalho original publicado em 1972-1973). 
Lacan, J. (2001a). L’étourdit. In J. Lacan, Autre écrits (pp. 449-495). Paris, France: Seuil. (Trabalho original publicado em 1972).

Lacan, J. (2001b). Présentation des Mémoires d'un névropathe. In J. Lacan, Autres écrits (pp. 213-217). Paris, France: Seuil. (Trabalho original publicado em 1966).

Lacan, J. (2001c). Télévision. In J. Lacan, Autre écrits (pp. 509-545). Paris, France: Seuil. (Trabalho original publicado em 1973).

Lacan, J. (2004). Le séminaire. Livre X. L'angoisse. Paris, France: Seuil. (Trabalho original publicado em 1962-1963).

Laurentin, R. (1988). Yvonne-Aimée de Malestroit, Les stigmates. Paris, France: O.E.I.L.

Laurentin, R., \& Mahéo, P. (1993). L'amour plus fort que la souffrance - Histoire médicale d'Yvonne-Aimée de Malestroit. Paris, France: F.X. de Guibert.

Laurentin, R. (1999). Biographie d'Yvonne-Aimée de Malestroit, Tome II. Paris, France: F.X. de Guibert.

Laurentin, R. (2000). Biographie d'Yvonne-Aimée de Malestroit, Tome III. Paris, France: F.X. de Guibert.

Luzzatto, S. (2007). Padre Pio, Miracoli e politica nell'Italia del Novecento. Turin, Italie: Einaudi.

Maître, J. (1993). Une inconnue célèbre, la Madeleine Lebouc de Janet. Paris, France: Anthropos.

Maleval, J.-C. (1997). Une épidémie américaine, Le syndrome d'enlèvement extraterrestre. In Le conciliabule d'Angers (pp. 145-161). Paris, France: Agalma/Seuil.

Menétrey-Monchau, D. (2010). Miraculés et stigmatisés. Paris, France: L'Éditeur.

Miller, J.-A. (1997). Des semblants dans la relation entre les sexes, Revue de la Cause freudienne, 36, 7-16.

Miller, J.-A. (1998). Un répartitoire sexuel, Revue de la Cause freudienne, 40, 7-27.

Miller J.-A. (1999). Les six paradigmes de la jouissance, Revue de la Cause freudienne, 43, 7-29.

Moreira Marcos, C. (2011). Considerações sobre o feminino e o real na psicanálise, Psicologia em Estudo, 16(1), 149-156.

Soler, C. (2006). Lo que Lacan dijo de las mujeres. Buenos Aires, Argentina: Paidos Psicologia Profunda.

Tenório, F., \& Costa-Moura F. (2014), Melancolia como presença real do objeto - uma abordagem lacaniana, Revista Latinoamericana de psychopatologia fundamental, 17(3), 469-484.

Tyszler, J.-J. (2011). A melancolia: Luto de um significante e objeto real da clínica. Revista Tempo Freudiano, Rio de Janeiro, 9, 69-102. 


\section{ARTIGOS}

Vinciguerra, R.-P. (2014). Femmes lacaniennes. Paris, France: Editions Michèle Yvonne-Aimée de Malestroit (1987). Ecrits spirituels. Paris, France: O.E.I.L.

\section{Resumos}

(The stigmata of the Passion of Christ: two cases of invention or mystical imposture)

Although cases of Christian stigmatization have become rare, general interest in this unusual physical phenomenon endures. Yet, a study of the cases of Madeleine Lebouc and Yvonne-Aimée de Jésus has revealed that their stigmata proceed either from self-mutilation or fraud. However, that's not the main point. Research into this peculiar form of relationship between a subject and his body proves to be quite rewarding, mainly because the phenomenon is sustained by a mystic relation to Jesus. Based on Freud's and Lacan's theories and on clinical elements, the present paper describes the two main functions of stigmata for these subjects, i.e. the processing of uncontrollable jouissance assigned to the body itself and the development of a process of representation that enables the subject to accept it and to deal with it.

Key words: Christian mysticism, stigmata, simulation, femininity, psychosis, jouissance

(Les stigmates de la Passion du Christ : deux cas d'invention ou d'imposture mystique)

Malgré la raréfaction des cas de stigmatisation chrétienne, la passion pour ce phénomène corporel insolite perdure. Pourtant une étude des cas Madeleine Lebouc et Yvonne-Aimée de Jésus révèle que les stigmates relèvent soit d'une automutilation, soit d'une feinte suggérant leur présence. Là n'est cependant pas l'essentiel. Il importe d'interroger ce mode original du rapport du sujet à son corps et ce d'autant plus qu'il se soutient d'un rapport mystique à Jésus. A la faveur des enseignements freudiens et lacaniens, cet article démontre, à partir de la clinique, les deux fonctions principales des stigmates pour ces sujets. Soit le traitement d'une jouissance folle appartenant au corps propre et d'un processus de représentation permettant de l'assumer et de la prendre en charge.

Mots clés: Mysticisme chrétien, stigmate, simulation, féminité, psychose, jouissance

(Los estigmas de la Pasión de Cristo: dos casos de invención o de impostura mística)

A pesar de los pocos casos de estigmatización cristiana, el interés por este insólito fenómeno corporal perdura. Un estudio de los casos de Madeleine Lebouc e YvonneAimée de Jesús revela que los estigmas delatan una automutilación o un ademán que sugiere su presencia. No obstante, esto no es lo esencial. Se muestra aún más fructífera una investigación basada en este modo original de relación entre el sujeto y su cuerpo 
y principalmente porque se sostiene en una relación mística con Jesús. Gracias a los aportes freudianos y lacanianos, este artículo demuestra clínicamente las dos principales funciones de los estigmas para estos dos sujetos, a saber: el tratamiento de un goce loco que pertenece al cuerpo propio y el advenimiento de un proceso de representación, permitiendo asumirlo y tratarlo.

Palabras clave: Misticismo cristiano, estigmas, simulación, feminidad, psicosis, goce

(Die Stigmata der Passion Christi: zwei Fälle von Erfindung oder mystischer Betrug)

Trotz der Seltenheit von Fällen christlicher Stigmatisierung besteht das Interesse an diesem ungewöhnlichen Körperphänomen weiter. Eine Untersuchung der Fälle Madeleine Lebouc und Yvonne-Aimée de Jésus zeigt, dass ihre Stigmata entweder auf Selbstverstümmelung oder Betrug beruhen. Dies ist jedoch nicht der wesentliche Punkt. Die Erforschung dieser eigentümlichen Form der Beziehung zwischen dem Subjekt und seinem Körper erweist sich als notwendig, vor allem weil das Phänomen sich auf eine mystische Beziehung zu Jesus stützt. In Anlehnung an die Theorien von Freud und Lacan enthüllt dieser Artikel anhand klinischer Elemente die zwei Hauptfunktionen der Stigmata für diese Subjekte: einerseits die Verarbeitung unkontrollierbaren Genießens [Jouissance], dass dem Körper selbst zugeordnet wird und anderseits das Entstehen eines Repräsentationsprozesses, der es dem Subjekt ermöglicht, dieses Genießen zu 296 akzeptieren und es zu verarbeiten.

Schlüsselwörter: Christliche Mystik, Stigmata, Simulation, Weiblichkeit, Psychose, Genießen

Citação/Citation: Hamon, R. (2019, junho). Os estigmas da Paixão de Cristo: dois casos de invenção ou de impostura mística. Revista Latinoamericana de Psicopatologia Fundamental, 22(2), 278-297. http://dx.doi.org/10.1590/1415-4714.2019v22n2p278.7.

Editoras/Editors: Profa. Dra. Ana Maria G. R. Oda e Profa. Dra. Sonia Leite

Submetido/Submitted: 29.10.2018 / 10.29.2018 Aceito/Accepted: 5.5.2019/5.5.2019 


\section{ARTIGOS}

Copyright: (C) 2009 Associação Universitária de Pesquisa em Psicopatologia Fundamental/ University Association for Research in Fundamental Psychopathology. Este é um artigo de livre acesso, que permite uso irrestrito, distribuição e reprodução em qualquer meio, desde que o autor e a fonte sejam citados / This is an open-access article, which permits unrestricted use, distribution, and reproduction in any medium, provided the original authors and sources are credited.

Financiamento/Funding: Este trabalho não recebeu financiamento / This work received no funding.

Conflito de interesses/Conflict of interest: $\mathrm{O}$ autor declara que não há conflito de interesses / The author has no conflict of interest to declare.

\section{Romuald Hamon}

Psychanalyste; Maître de Conférences en psychopathologie (HDR).

EA 4050, Université Rennes

2 Haute-Bretagne, Place Recteur le Moal

35043 Rennes Cedex, France

http://orcid.org/0000-0001-8202-4556

romuald.hamon@univ-rennes2.fr

This is an open-access article, which permits unrestricted use, distribution, the original authors and sources are credited. 